\title{
Milieu therapy as a method for improving the quality of life of the old people
}

\author{
Yevgen Oprya \\ Mykhailo Pustovoyt
}

\author{
Odessa National Medical University, Department of \\ Psychiatry, Narcology and Psychology \\ Odessa National Medical University, Department of \\ Psychiatry, Narcology and Psychology
}

Relevance. Nowadays, both in developing countries and in industrialized countries, there is a process of increasing life expectancy, which together with the problem of low birth rates leads to the phenomenon of "aging population". Providing care to the elderly is not only a purely medical problem, but the social aspect is equally important. An important component of the lifestyle of an elderly person is recreation - the processes of restoring vitality, relieving mental stress and recovery, carried out in various forms of recreation, nutrition, active or passive leisure. Modern society and the health care system face three most important tasks: continuing an active life with minimal losses from the disorders inherent in old age, combating high morbidity in old age and ensuring a dignified end to the lives of aging people.

Although the provision of medical and social assistance to the elderly is organized and provided as needed, ensuring the accessibility and sufficient presence in their lives of the social aspect and its communicative component is not supported in our country at the state level and is not regulated by law.

Purpose. The purpose of the work is to improve the quality of life of the elderly through the organization of the social component of life by arranging their leisure.

Results. To achieve this goal, it was proposed to use the principles and methods of milieu therapy, which means "treatment by the environment".

Most often, milieu therapy refers to a form of psychotherapy that involves the use of therapeutic communities. Considering the goal, milieu herapy fully covers and meets the goals of rehabilitation of the elderly, and as a social technology allows to create an active living environment that encourages older people to "independent actions", self-sufficiency, withdrawal from dependent moods and hyperprotection.

Milieu therapy allows to activate the living environment of such people in accordance with their needs, interests, psychophysical condition, rehabilitation potential; and to optimize the work of staff in the direction of improving the efficiency of activities that will have a direct impact on quality of life.

On the example of other countries, examples of the use of the principles of milieu therapy in the organization of daytime activities in the elderly are provided.

Conclusions. Providing leisure for the elderly will be able to improve their quality of life, reduce the prevalence of somatic diseases and the risk of developing psychosomatic conditions in them, and thus reduce the burden on health care facilities. And the use of the principles of milieu therapy to solve problems will allow to organize it as effectively as possible. 


\section{Relevance}

Nowadays, both in developing countries and in industrialized countries, there is a process of increasing life expectancy, which together with the problem of low birth rates leads to the phenomenon of "aging population". As a result, the WHO Regional Office for Europe has adopted the following classification of the elderly: 60 to 74 years old - elderly, 75 to 89 years old - old, and 90 years and more - long-livers. It should also be noted that in the presence of more than $8 \%$ of the population over the age of 65 , it is considered elderly. And in Ukraine this figure is about $20 \%[\underline{1}, \underline{2}$, 3].

It should also be noted that the provision of care to the elderly is not only a purely medical problem, and the social aspect is equally important [4]. The psychological characteristics of the elderly include the following symptoms: increased anxiety, distrust; tendency to isolation, depression; discernible lack of communication; inadequate assessment of symptoms of existing diseases: tendency to aggravation (exaggeration of existing signs of the disease), or to dissimulation (attribution of pathological changes to age) $[\underline{5}, \underline{6}, \underline{7}, \underline{8}, \underline{9}]$.

Usually, the system of life of an elderly person partially includes housekeeping, use of livelihoods (living space, food, clothing, household items, energy, sanitation). Another important component of an elderly person's lifestyle is recreation - the processes of restoring vitality (physical, intellectual, emotional), relieving of mental stress, recovery, carried out in various forms of rest, nutrition, active or passive leisure, treatment, taking tonics. A significant place in recreational processes is occupied by game entertainment practice, active (physical or intellectual) and passive. In addition, the lifestyle of the elderly includes such processes as self-development (physical, intellectual, aesthetic, creative), communication and everyday social relations, the formation and development of images of everyday worldview, raising grandchildren, forming their own image, as well as elements of religious and social practices (weddings, funerals).

Given the abovementioned facts, modern society and the health care system face three most important challenges. The first and most important is to continue an active life with minimal losses from disorders inherent in old age. The second, no less important and difficult is the fight against high morbidity in old age. The third task is to ensure a dignified end to the lives of aging people $[\underline{10}]$.

But although the provision of medical and social assistance to the elderly is organized and provided to such elderly people as needed, ensuring the availability and sufficient presence in their lives of the social aspect and its communicative component is not supported in our country at the state level and is not regulated by law.

\section{Purpose}

The purpose of the work is to improve the quality of life of the elderly through the organization of the social component of life by arranging their leisure.

\section{Results}

Within the framework of this problem, it would be appropriate to pay attention to such a method as milieu therapy $[11,12]$. The word "milieu" is French and means "environment". Milieu therapy means "treatment by the environment".

The environment means all components of the environment - physical (physical conditions, the environment in which a person lives), psychological and social components. Milieu therapy explores and uses all components so that they interact with each other and have a therapeutic effect on a client. Thus, it is the creation of an environment that would be more favorable for the life and 
rehabilitation of a client, an environment in which conditions would be created for the use of all methods of treatment - medical therapy, drug treatment, psychotherapy and any other type of influence and interaction. This is an environment in which every specialist and every method has its place. It is the cooperation and collaboration of team members who work in such conditions that is important. The actions of all employees should be coordinated and aimed at the same goal.

Most often, milieu therapy refers to a form of psychotherapy that involves the use of therapeutic communities. Patients join a group of 30 people for a period of 9 to 18 months. While in a group, patients are encouraged to take responsibility for themselves and other group members based on a hierarchy of collective relationships. Patients are expected to follow each other's rules, and older patients will model appropriate behaviors for new ones. If one patient breaks the rules, others who knew about the violation but did not intervene may also be punished to varying degrees depending on their involvement. It is believed that environmental therapy has value in the treatment of personality disorders and behavioral problems, and can also be used to stimulate residual cognitive and communicative abilities of a patient. The basics of milieu therapy are also often used as a factor in improving the quality of life of clients of psychoneurological boarding schools and as an organization of the agenda in psychiatric hospitals in developed Western countries (group psychotherapy, board games, picnics and dinners organizing for other patients).

The main purpose of using milieu therapy is to organize a comprehensive impact of environmental factors on improving well-being and, ultimately, improving the quality of life of clients, which is reflected in the following parameters:

- physical quality of life: the ability to live in comfort, adequate living conditions, feel, somatic comfort, which corresponds to the individual status of functional parameters, etc.;

- quality of mental life and psychological well-being: the opportunity to feel satisfaction, peace, joy, etc.;

- social quality of life: the opportunity to maintain family, cultural, economic relations, positive communication outside and inside the institution;

- spiritual quality of life: the opportunity to implement the meaning of life, goals, values, religious relations.

Based on these goals, milieu therapy covers as fully as possible and meets the goals of rehabilitation of the elderly $[\underline{13}, \underline{14}]$ :

1. reactivation - increasing the motor and cognitive activity of a patient;

2. resocialization - providing the elderly with equal social opportunities;

3. reintegration - adaptation of a geriatric patient to life in a microsocial environment.

Milieu therapy, as a social technology, allows to create an active living environment that encourages people with disabilities, including the elderly, to "independent activities", selfsufficiency, withdrawal from dependent moods and overprotection.

The main tasks of the technology are:

1. Creating comfortable living and psychological conditions for the stay of elderly and disabled people in the institution.

2. Formation of partnership relations between clients and employees of the institution showing by each employee in the provision of social services maximum sensitivity, courtesy, attention, endurance, foresight, patience, taking into account the physical and mental health of recipients of social services, formation of a positive attitude of recipients of social services to staff.

3. Creating a friendly team of recipients of social services.

4. Painless adaptation of recipients of social services in the institution: creating a favorable psychological microclimate, providing contacts with relatives, involvement of clients in 
various events, encouraging clients to be active, employee-regulated opportunity to express themselves.

Basic principles of milieu therapy:

- system and complexity in the organization of work with a client

- individual customer-oriented approach, partnership

- multidisciplinary team of highly qualified employees

- interdepartmental interaction and support of the recipient of social services

- determining the individual need for support and social services

- drawing up an individual plan for the provision of social services, schedule

- implementation of an individual plan, program implementation, adherence to a schedule

- individualized customer support

- evaluation of the effectiveness of the implemented plan, its correction if necessary

- monitoring customer satisfaction with living conditions and quality of social services

Achievement of these results requires maximum activation of the environment, which includes:

- employment;

- amateur classes;

- socially useful activities;

- sports and health activities;

- individual medical support;

- optimal organization of living space and meaningful leisure.

In the implementation of milieu therapy systematic and planned work is carried out with the following factors of the social environment of clients:

- interior factor;

- socio-psychological and pedagogical factor;

- medical factor.

Interior factor - the formation of an accessible, safe, comfortable, convenient environment: the design of all premises, the landscaped area of the institution, ensuring accessibility and comprehensive security.

Socio-medical factor - means of care and rehabilitation, methods of providing medical services, modern medical equipment and methods of rehabilitation.

Socio-psychological pedagogical factor - the creation of a favorable psychological climate in the institution; preservation and maintenance of the client's social activity; structured time; organization of employment; organization of meaningful leisure; inclusion in cultural and mass, informational and educational, sports and health events, etc.

Among the most popular activities implemented by clients in the framework of milieu therapy, we can highlight the following:

- physical culture and health (exercise classes, Nordic walking, psychogymnastics, etc.);

- cultural and leisure (clubs, art therapy, entertainment cultural events, etc.);

- informational and educational (thematic conversations, excursions, visits to the library);

- manageable occupational therapy (embroidery, knitting, sewing, care for houseplants and animals);

- classes on social and domestic orientation and the formation of self-care skills in the framework of occupational therapy;

- classes in the room of psychological relief (including music therapy and aromatherapy); 
- classes in garden therapy and animal therapy as part of ecotherapy.

These activities help us to organize a focused lifestyle of a client, maintain physical health, maintain physical and social activity, activate intellectual resources, create a favorable psychological climate, provide quality conditions for care and treatment.

In summary, it can be noted that the effectiveness of milieu therapy is confirmed by the positive dynamics of clients on the following indicators:

- acquisition and strengthening of self-service skills;

- expanding the range of interests, restoring and developing communication skills;

- increasing satisfaction with treatment, staff attitude, service;

- intensification of leisure, participation in public events;

- increasing the degree of life satisfaction and a positive worldview in general.

At client's stabilization of an emotional background, decrease in frequency of emergence of depressive conditions is observed, tendencies to decrease of aggression and conflict are noted.

Thus, milieu therapy allows to activate the environment of clients' life in accordance with their needs, interests, psychophysical condition, rehabilitation potential; and to optimize the work of staff in the direction of improving the efficiency of activities that directly affect the quality of life of clients of the social service institution.

As an example of the organization of care for the elderly, there are relevant programs in both developing countries (Cuba) and in countries with developed economies (the USA, Italy, Hong Kong, Singapore). The only difference is that in developed countries it is in most cases a paid service, and in Cuba - it is a free social program.

In Cuba, since 2009, care for the elderly has been provided within three sub-programs: institutional, hospital and community one, with the latter being used in the vast majority of cases. It provides for periodic medical examinations in family medical consultations; interest groups for the elderly; day care centers for the elderly, home help; training courses for care professionals; family canteens and university departments of education of the elderly. For example, in hard-to-reach areas of Cuba and the capital, there are 1,578 television rooms with the opportunity to spend the day for the elderly. These nursing homes are very similar to the centers that were also established in the United States, particularly in Chicago. The function of such homes is primarily to create a social environment so that older people, who so often feel lonely, can meet other peers and share their problems. Such houses provide breakfast, lunch and dinner. Often in such houses it is also possible to perform various types of needlework, there is the exchange of books and they provide a certain level of physical activity in the form of selected exercises.

In metropolitan cities such as Hong Kong and Singapore, such centers for the elderly are located on the middle floors of multi-story condominiums and function as trust centers that create a warm and familiar environment for the elderly. They provide a wide range of social, entertainment and support services to help older people function properly in society (meet and socialize with neighbors, play sports and take part in fun and interactive activities). Such centers can even be equipped with gardens and orchards of the "winter garden" type, as well as organized a partial joint pastime with the pupils of preschool educational institutions, which are located on other floors of the same complexes. Since the elderly are an important resource and many of them have a wealth of experience and valuable skills that can be used through active contact with the community, and thus contribute to the education of future generations.

Active aging programs are quite popular in the United States, which encourage the elderly to remain active, healthy and socially active. Along with a variety of exercises, including elastic bands and low-load aerobics, seniors' health seminars are held to learn more about nutrition, healthy 
aging, and advice on choosing a healthier lifestyle to improve and maintain their physical, mental and functional health. There can also be healthy cooking lessons (older people can learn to cook healthy meals with the help of instructors in real life) or social activities (older people can keep their minds active and make new friends through social activities such as karaoke and a coffee corner).

In Italy, day care centers for the elderly are organized, where they gather for socializing, spending time together and group games in the open air.

Summarizing the need to organize leisure for the elderly, it should be noted that already in the "Diary of an Old Doctor" Mykola Pyrogov emphasized that the mental attitude, mood of a patient is a powerful factor that often determines the course of treatment. And it is no coincidence that the Christian commandments, among the seven deadly sins, includes despair. In other words, a person's attitude to the prospect of a better life has a decisive impact on his/her health. If a person's mood for a full life is lost, it is useless to talk about his/her health. The ability of a person to adapt to a changing environment, living conditions is the main elixir of health.

\section{Conclusions}

Providing leisure for the elderly will be able to improve their quality of life, reduce the prevalence of somatic diseases and the risk of developing psychosomatic conditions in them, and thus reduce the burden on health care facilities. And the use of the principles of milieu therapy to solve given problems will allow to organize it as effectively as possible.

\section{Additional information}

\section{Competing interests}

The author declares that no competing interests exist.

\section{References}

1. Lebanon EM. Comprehensive demographic forecast of Ukraine for the period up to 2050 (team of authors). Kyiv: Ukrainian Center for Social Reforms; 2006:138.

2. Tchaikovsky VV, Pinchuk IYa. Demographic forecasts for Ukraine. News of medicine and pharmacy. 2010;13(333):13-4. URL: http://www.mif-ua.com/archive/article/13392

3. Gubachev YM, Makienko VV. Geriarthric problems of family medicine. SpB: St Petersburg; 2000:70.

4. Pustovoyt MM. Diathesis-stress model of involutional psychoses. Archives of psychiatry. 2018;2(93):87-101. URL: http://ndips.org/assets/ap_2_2018_block_new.pdf

5. Chaban OS, Khaustova OO. Mental health of the elderly: problems of diagnosis and therapy. Neuronews. 2013;12(1):3-8.

6. Pinchuk IJ, Tchaikovsky VV, Stadnyk LA, et al. Current issues of gerontopsychiatry: a textbook. Ternopil: Termograf Publishing House; 2010:431.

7. Maruta NO, Korostiy VI, Kozhyna HM, et al. Handbook of family doctor on psychosomatics. Kyiv: Health; 2012:384.

8. Shapkin VE. The role of a general practitioner in providing medical care to elderly families. South Ukrainian Medical Scientific Journal. 2013;3(3):144-7.

9. Maruta NO, Yavdak IO, Cherednyakova OS. The system of therapy of endogenous depression with suicidal risk in the elderly. Health of Ukraine, Neurology, Psychiatry, Psychotherapy. 2012;3(22):22-3.

10. Yarygina VN, Melentyeva AS. Guide to Gerontology and Geriatrics, Volume 1: Fundamentals of gerontology. General geriatrics.Moscow: GEOTAR-Media;2010:720.

11. Gunderson JG, Will OA, Mosher LR. Principles and Practice of Milieu Therapy. New York: 
Jason Aronson Inc; 1981:189.

12. Goldsmith JM, Sanders J. Milieu therapy: significant issues and innovative applications. New York: The Haworth Press, Inc; 1993:120.

13. Pogodina AB, Gazimov AH. Fundamentals of gerontology and geriatrics. Rostov: Phoenix; 2007:253.

14. Chaban OS, Khaustova OO. Psychosomatic comorbidity and quality of life in elderly patients. Neuronews; 2016;12(1):8-12. 